Supplement of Biogeosciences, 15, 2231-2249, 2018

https://doi.org/10.5194/bg-15-2231-2018-supplement

C Author(s) 2018. This work is distributed under

the Creative Commons Attribution 4.0 License.

(c) (1)

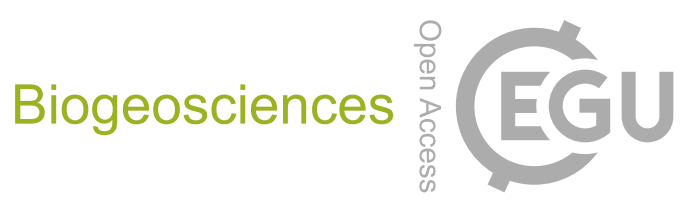

Supplement of

\title{
Contribution of fine tree roots to the silicon cycle in a temperate forest ecosystem developed on three soil types
}

Marie-Pierre Turpault et al.

Correspondence to: Marie-Pierre Turpault (marie-pierre.turpault@inra.fr)

The copyright of individual parts of the supplement might differ from the CC BY 4.0 License. 


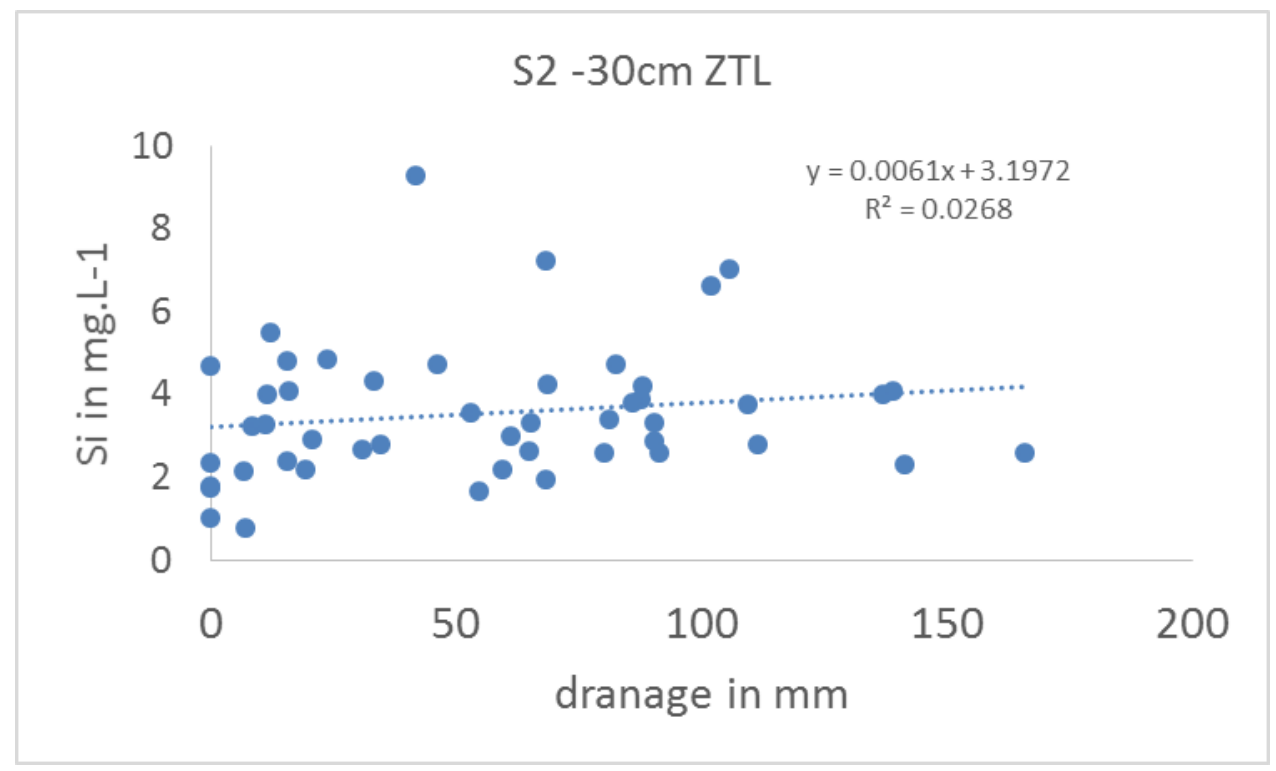

Figure S1: Relationships between drainage and ZTL Si concentration at $-30 \mathrm{~cm}$ in S2 (eutric cambisol) 


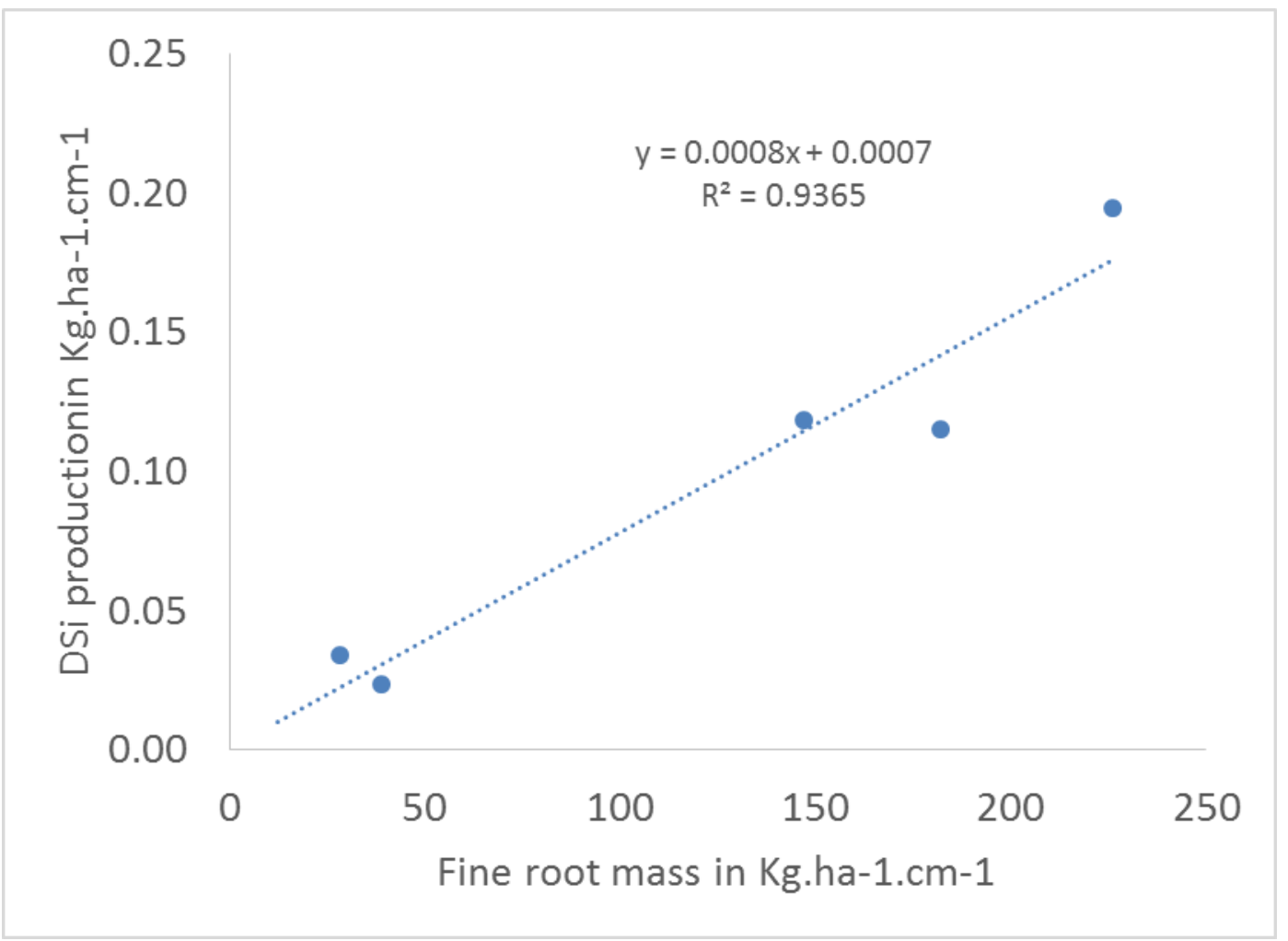

Figure S2: Relationships in fine root content and annual Si production in the $10-60 \mathrm{~cm}$ soil layers. 